\title{
A Comparison of RFID and Visual Ear Tag Retention in Dairy Cattle in Malaysia
}

\author{
Salina $\mathrm{AB}^{1}$, Hassan $\mathrm{L}^{1}$, Saharee $\mathrm{AA}^{1}$, Stevenson $\mathrm{MA}^{2}$, Ghazali $\mathrm{K}^{3}$ \\ ${ }^{1}$ Faculty of Veterinary Medicine, Universiti Putra Malaysia, 43400 Serdang, Selangor, Malaysia \\ ${ }^{2}$ Faculty of Veterinary and Agricultural Sciences, The University of Melbourne \\ ${ }^{3}$ Department of Veterinary Services, Wisma Tani, 62630 Putrajaya, Malaysia \\ salina_alin4280@yahoo.com
}

\begin{abstract}
Animal identification is a basic tool to identify animals for all activities including for farm management. Electronic ear tag using radio frequency identification (RFID) technology has been newly introduced in the dairy population. The objective of this study was to evaluate the retention of RFID and visual ear tag of various brands in dairy cattle in Malaysia. A field trial was carried out on 102 dairy cattle to assess the retention of four brands of RFID tags (Allflex, Cybortra, TSG and Ecosensa) and three brands of visual ear tags (Allflex, Cybortra, and Ecosensa). The presence or lost of the tag was evaluated every three month for one year. Cybortra RFID tag and Allflex visual ear tag have the highest percentage of tag retention at 81.5 and $96.1 \%$, respectively when compared to other brands. The percentage of cattle that lost both of its tag (RFID and visual ear tag) was low at $3.7 \%$ for Cybortra brand and $0.0 \%$ for Allflex brand. Whereas, the percentage of cattle that lost its single identification was highest (45.5\%) for TSG RFID tag. Severe ear necrosis was observed to be one of the reasons that influence the tag lost. Cattle with two identifications was found to be traced more efficiently compared to the cattle with single identification.
\end{abstract}

Key Words: RFID Tag, Visual Ear Tag, Retention, Dairy Cattle

\section{INTRODUCTION}

Animal identification is an important tool for good farm management and the most important element for animal traceability. There are several types of cattle identification used worldwide which include ear tag, tattoo, branding, neck collar, nose printing and paint marking (Neary \& Yager 2002). In dairy animals, ear tag is the most common identification used, besides branding, neck collar, leg tag and tail tag. Visual ear tag is a non-electronic tag that can be written on using permanent marking ink or laser-printed. Recently, electronic ear tag known as radio frequency identification (RFID) tag has been introduced and is said to be more efficient to record the daily management and production of dairy animals in China (Hong-da 2012). The technology is assumed to be safe and does not cause stress to the animal nor influence the milk yield and quality (Stankovski et al. 2012). The use of electronic identification is highly recommended when there is a need to keep good record of dairy animals. A good identification would help a lot and can minimize a human error, such as experienced by European Union (Wismans 1999). However, cost is always a farmers concern when something new is implemented.

In Malaysia, the use of RFID tag in beef cattle has been encouraged on a voluntary basis since 2009. However, the usage is sporadic as requirement for animal identification is necessary when animals are to be moved from one location to another. RFID tag is only compulsory for imported animals. The RFID tag usage in dairy cattle is less common especially among the smallholders. To our knowledge, there has not been any study conducted to assess the tags used in Malaysia. This study aims to evaluate a few brands of RFID and visual ear tags in terms of their retention in dairy cattle. The findings from this 
study can provide the government, farmers and traders suggestion on the most suitable types of tags and methods of tagging animals to improve tag retention.

\section{MATERIAL AND METHODS}

A one-year field trial was carried out in two dairy farms owned by the Department of Veterinary Services, Malaysia (DVS). Both farms practiced semi-intensive system where the animals graze on pasture after milking in the morning and herded in shed in the evening. A total of 102 dairy cattle aged between 5 months to 14 years old were involved in this study. The breed of the dairy cattle is Mafriwal which is the Sahiwal-Friesian crossbred (Panandam \& Raymond 2005).

Dairy animals were divided into four groups and each group was tagged with a different brand of RFID and/or visual ear tags. The brands tested were Allflex, Cybortra, TSG and Ecosensa. Alfflex and Cybortra consisted of male and female RFID button tag, and male and female visual ear tag. TSG comprised of male and female RFID button tag only, while Ecosensa was a combination of female RFID button tag and male visual ear tag (Figure 1). Therefore, four brands were tested for RFID tags and three brands were tested for visual ear tags. The RFID tags were full-duplex, and both the RFID and standard visual ear tag numbers were laser printed. Animals that received two tags (RFID and visual ear tags) were tagged in separate ears.

The location to place the tag on the ear was one of the factor that could minimize the risk of the tag being caught and lost. In this study, we have standardized the tagging process and educated the assistants who help us tagged the animals. This procedure was consistent with a practiced done in Australia (Britt et al. 2013). A proper restraining was needed to tag the tag at the right place and minimize injury to the animals and the tagger as well. The tag retention for both RFID and visual ear tags were evaluated every three month for one year. The tag lost percentage was analysed across tag types using statistical software SPSS version 20, IBM Corporation, 2011.

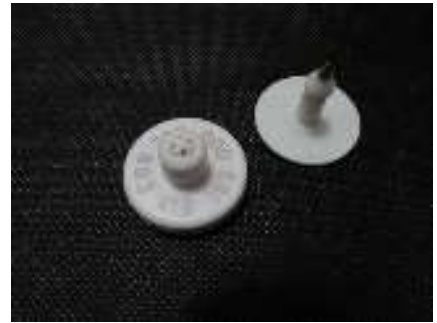

Brand: TSG

RFID button tag (male and female)

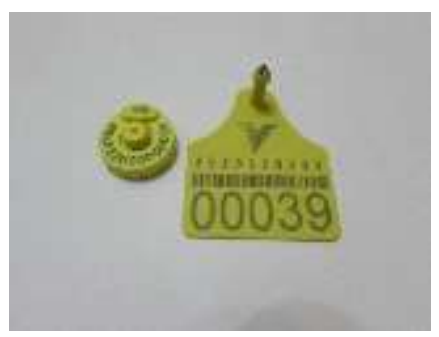

Brand: Ecosensa

RFID button (female) and visual ear tag (male)

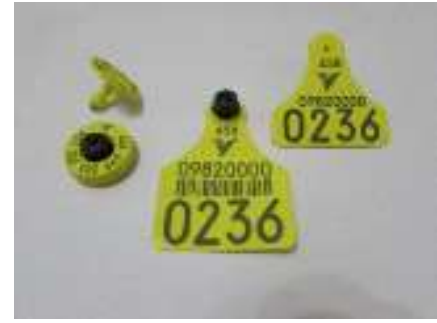

Brand: Allflex

RFID button tag (male and female) and visual ear tag (male and female)

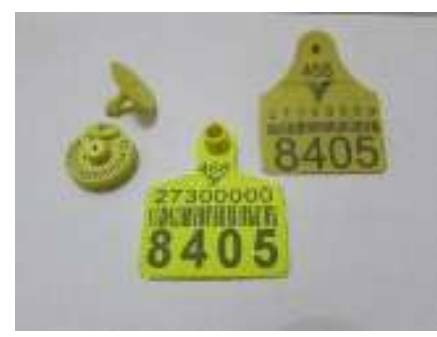

Brand: Cybortra

RFID button tag (male and female) and visual ear tag (male and female)

Figure 1. Brand and description of RFID and visual ear tags 


\section{RESULTS AND DISCUSSION}

Out of 102 cattle that were tagged at the beginning of the study, 11 animals (10.8\%) were lost due to deaths, culled or were sold by the end of the study. The number of animal present during each evaluation decreased from one sampling to another (Table 1). The percentage of tag lost were 18.5; 22.7; 31.4; and 45.5\% for Cybortra, Ecosensa, Alfflex and TSG RFID tag, respectively. For visual ear tag, Alfflex has showed the lowest tag lost (3.9\%) compared to the other brands. Within one year, only one cattle $(3.7 \%)$ using Cybortra brand lost both it tags, while none of cattle lost both its tag when using Alflex brand. On the other hand, $22.7 \%$ and almost half $(45.5 \%)$ of the cattle with Ecosensa and TSG tag lost its single identification, respectively. As the retention rate for TSG RFID tag was low (54.5\%), this brand should not be recommended for farm use. Animal with two identifications are more likely to be trace, as one serve to back the other up in cases of lost identification. This is an agreement with the findings by Fosgate et. al (2006) who found that the use of ear tag alone in buffalo was not sufficient for long-term identification. Additional method of identifications are needed to manage animal populations.

Table 1. Number of animals present during each evaluation and percentage of RFID and visual ear tag lost

\begin{tabular}{|c|c|c|c|c|c|c|c|c|c|c|}
\hline \multirow{2}{*}{ Tag brands } & \multirow{2}{*}{$\frac{0 \text { month }}{\mathrm{n}}$} & \multicolumn{2}{|c|}{3 month } & \multicolumn{2}{|c|}{6 month } & \multicolumn{2}{|c|}{9 month } & \multicolumn{2}{|c|}{12 month } & \multirow{2}{*}{$\begin{array}{c}\text { Total lost } \\
(\%)\end{array}$} \\
\hline & & $\mathrm{n}$ & Lost & $\mathrm{n}$ & Lost & $\mathrm{n}$ & Lost & $n$ & Lost & \\
\hline \multicolumn{11}{|l|}{ RFID tag } \\
\hline Allflex & 28 & 28 & 4 & 28 & 3 & 27 & 0 & 23 & 1 & $8(31.4)$ \\
\hline Cybortra & 28 & 27 & 1 & 27 & 1 & 27 & 1 & 26 & 2 & $5(18.5)$ \\
\hline TSG & 23 & 23 & 5 & 22 & 1 & 21 & 1 & 21 & 3 & $10(45.5)$ \\
\hline Ecosensa & 23 & 22 & 0 & 22 & 3 & 22 & 1 & 21 & 1 & $5(22.7)$ \\
\hline \multicolumn{11}{|c|}{ Visual ear tag } \\
\hline Allflex & 28 & 28 & 0 & 28 & 1 & 27 & 0 & 23 & 0 & $1(3.9)$ \\
\hline Cybortra & 28 & 27 & 0 & 27 & 2 & 27 & 1 & 26 & 0 & $3(11.1)$ \\
\hline Ecosensa & 23 & 22 & 0 & 22 & 3 & 22 & 1 & 21 & 1 & $5(22.7)$ \\
\hline
\end{tabular}

During the study, a total of 16 animals suffered adverse side effect from the tagging. Severe ear necrosis was one of the reasons that influence the tag lost (Figure 2 and 3) besides the quality of the tag that was too tight causing restricted airflow. Therefore, adjustment on the space between the male and female portions may overcome this situation.

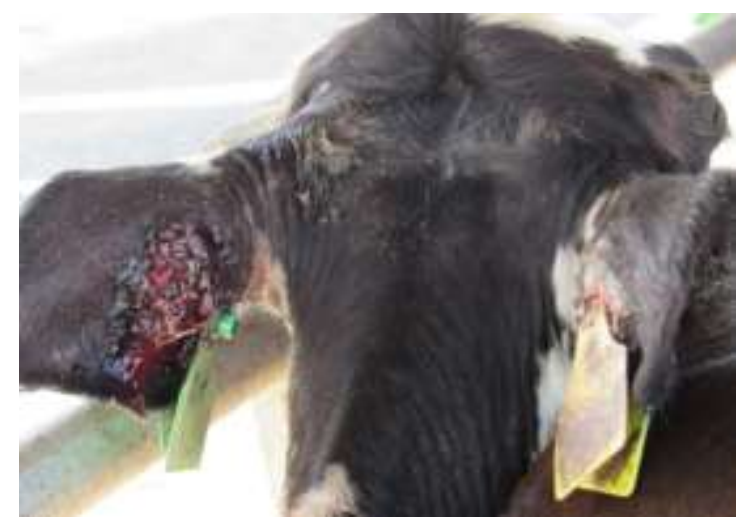

Figure 2. Ear necrosis in cattle with Cybortra RFID and visual ear tag 


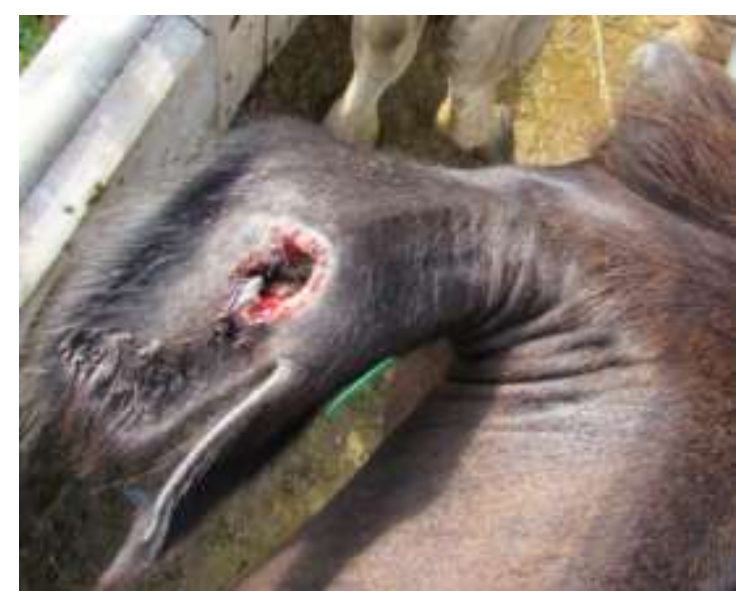

Figure 3. Alfflex RFID tag lost and the ear necrosis

The tag that performed poorly in this study was TSG RFID tag. This tag is also the cheapest and is popularly used by local farmers. Among the tags used in this study, the price ranged between RM 3.10 and RM 10.00. Cybortra, which have the longest retention for RFID tag, in this study is RM 6.30 each as compared to RM 3.10 for TSG. For visual ear tag, Allflex which have lowest tag lost, is RM 7.30 each as compared to RM 5.50 for Cybortra and RM 8.90 for Ecosensa. The choice of tags should be balanced between cost and quality. It is worthless to choose cheap identification that can only last for few days or months. However, it is also not viable for farmers who only have few animals to buy expensive identifications and equipments. The selection of the best type of identification to be used should be parallel with the needs and the goal to be achieved (Neary \& Yager 2002).

\section{CONCLUSION}

Cybortra RFID tag have the highest percentage of tag retention at $81.5 \%$. For visual ear tag, the retention was highest $(96.1 \%)$ for Alflex. From this study, we found that time is definitely a factor for tag lost. The longer the tag been used, the greater incidence of tag lost. Therefore, we recommend that each cattle to have two identifications that acts as a backup in case of lost identification.

\section{ACKNOWLEDGEMENT}

The authors thank the Director General of DVS Malaysia, DVS officers and Public Service Department Malaysia for their support in this study.

\section{REFERENCES}

Britt AG, Bell CM, Evers K, Paskin R. 2013. Linking live animals and products: Traceability. Rev Sci Tech. 32:571-582.

Fosgate GT, Adesiyun AA, Hird DW. 2006. Ear-tag retention and identification methods for extensively managed water buffalo (Bubalus bubalis) in Trinidad. Prev Vet Med. 73:287-296.

Hong-da, Wu. 2012. Application of radio frequency identification (RFID) in dairy information management. J Northeast Agric Univ.19:78-81.

Neary M, Yager A. 2002. Methods of livestock identification. West Lafayette (US): Purdue University. 
Panandam JM, Raymond AK. 2005. Development of the Mafriwal dairy cattle of Malaysia. AGTR case study. Nairobi (Kenya): ILRI.

Stankovski S, Ostojic G, Senk I, Rakic-Skokovic M, Trivunovic S, Kucevic D. 2012. Dairy cow monitoring by RFID. Sci Agric. 69:75-80.

Wismans WMG. 1999. Identification and registration of animals in the European Union. Comput Electron Agric. 24:99-108. 